\title{
Restricted processing of simultaneously presented brightness and pattern stimuli in pigeons
}

\author{
PHILIPP J. KRAEMER \\ State University of New York, Binghamton, New York \\ and \\ WILLIAM A. ROBERTS \\ University of Western Ontario, London, Ontario, Canada
}

\begin{abstract}
Performance during simultaneous matching-to-sample was assessed in pigeons presented with element and compound visual samples. In Experiment 1, pigeons were trained with a symbolic matching procedure, in which different pairs of colored comparison cues presented on side keys were mapped onto a bright or dim houselight as one pair of sample stimuli and onto vertical and horizontal lines on the center key as a second pair of sample stimuli. They were then tested with houselight-line compound samples. It was found that matching accuracy for lines was significantly diminished with compound samples relative to element samples. Conversely, houselight intensities were matched as well with compound samples as with element samples. In Experiment 2, a similar effect was found with pigeons that had been trained to match only line samples. In Experiment 3, it was discovered that sample duration had no influence on the matching deficit found with lines following compound samples in birds either trained or not trained to match houselight intensities. These results, taken in combination with recent findings from experiments with auditory-visual compounds, suggest a restricted processing account of pigeon processing of simultaneously presented stimuli from different sources.
\end{abstract}

The matching-to-sample procedure has been used frequently to study stimulus processing in animals. A number of these studies have found that matching accuracy is generally higher with element samples than with compound samples (Maki \& Leith, 1973; Maki \& Leuin, 1972; Maki, Riley, \& Leith, 1976; Roberts \& Grant, 1978). Two major theoretical alternatives have been proposed to account for this effect. A divided- or sharedattention analysis argues that organisms have a limited attentional capacity and cannot attend to all components of a compound sample at the same time. Consequently, attention must be shared between components, and each component does not receive the degree of attention it would if presented alone. It is this diminished attention that is held to be responsible for the matching deficit (Maki et al., 1976; Riley, 1984; Riley \& Leith, 1976; Riley \& Roitblat, 1978). Evidence in support of this position includes the finding that the matching deficit with compound samples is symmetrical; that is, when either element of a compound sample is tested, a matching deficit is observed, relative to trials in which that same element is presented alone as a sample. In addition, the theory sug-

This research was supported by National Sciences and Engineering Research Council Grant A7894 to William A. Roberts. Requests for reprints should be sent to Philipp J. Kraemer, Department of Psychology, State University of New York, Binghamton, NY 13901 gests that separation of the components of a compound will reduce attention to these cues and further reduce matching accuracy, and evidence in support of this prediction has been reported (Lamb \& Riley, 1981). Finally, there is some evidence indicating that attention to particular stimulus dimensions can be manipulated through training, which is also consistent with a shared-attention analysis (Leith \& Maki, 1975).

The evidence in favor of shared attention, however, has not been conclusive. For example, the compound element deficit has not been found to disappear or diminish with extended sample durations, as the theory would predict (Lamb \& Riley, 1981; Roberts \& Grant, 1978; Santi, Grossi, \& Gibson, 1982). In addition, the effect has been found with monkeys even in simultaneous matching-tosample. Under these conditions, the subject has unlimited time to determine the relevant component of the compound and extract the appropriate information before responding (Cox \& D'Amato, 1982). Thus, compound element deficits found in simultaneous matching-to-sample challenge the limited-capacity assumption held by most shared-attention accounts.

The other major theoretical alternative is the generalization decrement hypothesis. According to this approach, the compound element matching deficit is due to a physical dissimilarity between compound samples and comparison stimuli. The typical test procedure has been to present 
element comparison stimuli following compound samples. For instance, a compound sample composed of white vertical lines presented on a red background might be followed by red and green comparison keys, if color was the dimension being tested, or by comparison keys with either vertical or horizontal lines, if line orientation was being tested. Thus, the matching deficit found with this procedure may be a function of stimulus generalization decrement, due to the fact that the test stimuli are physically different from the compound sample stimuli (Cox \& D'Amato, 1982). When the test procedure is changed, so that one of the comparison stimuli physically matches the compound sample, the compound element deficit is often reduced or eliminated (Maki et al., 1976; Santi et al., 1982).

As with the shared-attention analysis, the evidence has not unequivocally supported the generalization decrement hypothesis (Maki et al., 1976; Roberts \& Grant, 1978). As an example, a recent study by Kraemer and Roberts (1985) reported a compound element deficit in a situation in which the stimulus generalization confound was avoided. Rather than using an identity matching-to-sample procedure, in which matching involves physical characteristics of the stimuli, a symbolic matching procedure was used. Pigeons were trained to match high- and lowfrequency tones to two different visual comparison stimuli and two ambient color samples to two other visual comparison stimuli. They were then tested with element and compound samples. Despite the absence of any similarity between samples and comparisons, a compound element deficit was still obtained.

Although these results do not seem to support a generalization decrement hypothesis, other findings from the Kraemer and Roberts study are also inconsistent with assumptions of a shared-attention analysis. For example, in most studies that have reported compound element deficits, these deficits have been approximately symmetrical, in that performance on both members of the compound has been inferior to accuracy with corresponding element samples. This finding is consistent with the assumption that attention is distributed among components of a compound sample and that these components receive less processing than they would if presented as element samples. In the Kraemer and Roberts (1985) study, however, an asymmetrical deficit was obtained. Tones were matched less well when presented in compound with colors than when presented alone, but colors were matched equally well when presented alone as when in compound with a tone. In addition, these effects were found both in 0-sec delayed matching and in simultaneous matching; the latter result is inconsistent with a sharedattention analysis based on the assumption of a timeconstrained attentional capacity.

The results of the Kraemer and Roberts (1985) study are perhaps more compatible with a restricted processing analysis. This approach suggests that organisms may encounter situations in which they limit processing to one component or dimension of a stimulus while ignoring others. Rather than dividing attention among components of a compound sample, as suggested by the sharedattention analysis, it is assumed that attention is unilaterally allocated to one of the components. In addition, it is assumed that restricted processing is not a function of limited attentional capacity or an artifact of insufficient processing time as maintained by shared-attention models. Thus, it is suggested that even with simultaneous matching, in which processing-time constraints are avoided, a matching deficit may still occur for one component of a compound. For example, pigeons in the Kraemer and Roberts study may have been attending exclusively to the visual component of the visual-auditory compounds.

An important question for such an analysis is why processing would be restricted to visual signals rather than auditory signals during compound sample presentations. One possibility is that pigeons may generally give priority to visual signals over auditory signals because of an innate visual dominance. Another possibility is that the visual nature of the comparison stimuli may have biased attention toward visual signals. Also, Kraemer and Roberts (1985) observed that matching of visual samples was acquired more rapidly than the matching of auditory samples. Thus, perhaps greater discriminability for the visual samples could have biased attention toward the visual component.

In this study, we attempted to examine further the processing of compound samples. Pigeons were trained on two separate simultaneous matching-to-sample problems, both involving visual samples. In one problem the samples consisted of different line orientations; in the other, the samples were two levels of houselight illumination. Houselight was chosen as one of the stimulus dimensions because of an interesting effect reported by Kraemer and Roberts (1985, Experiment 2). It was found that the presence of a houselight during either auditory or visual samples disrupted matching performance. A simple explanation for this effect might be that the houselight caused a perceptual degradation of the sample stimuli. A more interesting possibility is that pigeons restricted processing to the houselight illumination, or other visual cues made available by the houselight, and failed to process the nominal sample, whether it was a tone or a color. It may be that pigeons possess an attentional hierarchy that extends beyond simple modality differences. Accordingly, compound visual signals, with components independently localized, might produce an effect comparable to that found with auditory and visual samples.

\section{EXPERIMENT 1}

Six pigeons were trained on two symbolic simultaneous matching-to-sample problems. One of these problems presented high or low houselight illumination as samples, each of which was mapped onto a different colorcomparison stimulus. In the other problem, the samples were three vertical or horizontal lines presented on a pecking key, each of which was mapped onto two other color- 
comparison stimuli. After both problems were acquired, test sessions were introduced in which both compound and element samples were presented.

\section{Method}

Subjects. Six experimentally naive adult Silver King pigeons served as subjects. The birds were housed in individual wire cages located in a single housing room. Each bird was maintained at its $80 \%$ free-feeding weight throughout the experiment. The housing room was kept on a 14-h-on/10-h-off light cycle, and all pigeons were tested at the beginning of the light-on period.

Apparatus. The test apparatus consisted of a standard three-key operant chamber for pigeons (see Roberts \& Kraemer, 1982). Multistimulus projectors, located behind each pecking key, presented solid blue, yellow, red, or green colored fields on each of the two side keys and either three vertical or three horizontal white lines on the center key. Houselight samples were presented with a .1-A, 28-V lamp, which was located above the center key and mounted in a metal shield that covered the top half of the bulb. Luminance levels for the four sample stimuli were measured with a Tektronix Model J16 digital photometer, placed directly against either the houselight or the center key. The luminance of the vertical and horizontal line samples measured 33 and $35 \mathrm{~cd} / \mathrm{m}^{2}$, respectively; the high and low houselight intensities measured 7,500 and $4 \mathrm{~cd} / \mathrm{m}^{2}$, respectively. All trial event programming and response recording was controlled by a Commodore 64 computer and a locally constructed computer interface.

Procedure. Initially, all pigeons were hand-shaped to peck a solid white center key for mixed grain reinforcement. This preliminary training was followed by Phase 1 of acquisition, in which each bird was trained on a simultaneous symbolic matching-to-sample problem. For 3 randomly selected birds, this problem consisted of houselight samples, and, for the other 3 birds, the samples were line orientations. Birds given houselight samples were reinforced for pecking a red side key following a bright houselight (BL) and a green side key following a dim houselight (DL). For the other 3 birds, pecks to a red eide key were reinforced following vertical lines (V) and pecks to a green side key were reinforced following horizontal lines $(H)$. Each subject was tested on one 48-trial session each day. Each session contained an equal number of trials with the two samples, and the left/right position of the correct side key was balanced across samples. Two different randomly arranged trial orders were alternated regularly across sessions.

Each trial began with the presentation of a sample for $4 \mathrm{sec}$, followed by the onset of red and green side keys. The sample and side keys remained on until a peck was registered on one of the side keys. Pecks on the correct side key were followed immediately by termination of all stimuli and activation of the food hopper, which provided grain for 2 sec. Pecks on the incorrect side key resulted in termination of the stimuli. A 20-sec intertrial inter$\mathrm{val}$, spent in complete darkness, followed either a peck to the incorrect side key or termination of the food reward. Daily sessions were continued until the subject achieved a score of $85 \%$ or greater correct responses in three consecutive sessions. Phase 2 of acquisition began with the following session.

During Phase 2, birds that had been matching houselight samples in Phase 1 now were given line samples, and birds that had been trained with line samples now were given houselight samples. For birds given line samples, pecks to a blue side key were reinforced following $\mathrm{V}$ samples, and pecks to a yellow side key were reinforced following $\mathrm{H}$ samples. Similarly, birds now trained with houselight samples were reinforced for pecking a blue side key following BL samples and a yellow side key following DL samples. Training during Phase 2 followed the procedure that had been used in Phase 1. All birds completed Phase 2 when they had achieved three consecutive sessions of $85 \%$ or greater correct choices. All birds then received two sessions that involved mixed presentations of the two sample types. An equal number of BL, DL, V, and $\mathrm{H}$ samples were presented in a random order, with the spatial position of the correct side key balanced across samples. Experimental testing began with the following session.

Each test session consisted of 16 element trials, with each of the samples (BL, DL, V, and H) tested on four trials. The remaining 32 trials involved presentation of compound samples; the compounds were $\mathrm{BL}+\mathrm{V}, \mathrm{BL}+\mathrm{H}, \mathrm{DL}+\mathrm{V}$, and $\mathrm{DL}+\mathrm{H}$ and involved simultaneous exposure of the components. Each of these compounds was presented for eight trials, four trials in which the side keys appropriate for the houselight samples were presented and four trials in which the side keys appropriate for the line samples were presented. Responses to side keys that matched appropriate elements of the compound samples were reinforced and counted as correct. The spatial position of the correct side key was balanced across trial types. Two different random orders of trial presentation were alternated regularly across the 32 test sessions.

\section{Results and Discussion}

Birds trained to match houselight samples reached criterion in 11.8 mean sessions, whereas birds trained to match lines reached criterion in $\mathbf{4 2 . 2}$ mean sessions; the difference in mean sessions was significant $[t(5)=3.04$, $p<.05]$. The mean percent correct responses for each trial type tested during experimental sessions is displayed in Figure 1. It can be seen that performance was consistently high across the conditions in which the houselight sample was tested (light alone, light $+\mathrm{V}$, and light $+\mathrm{H}$ ), and statistical analysis indicated no significant difference across these conditions $[F(2,5)=2.5, p<.01]$. Also, a comparison of matching accuracy for the two houselight samples on compound trials revealed no significant difference between BL (89.0\%) and DL (95.0\%) samples $[t(5)=.49, p>.05]$. Conversely, on lines tests, significant differences appeared between the lines, lines $+B L$, and lines $+D L$ conditions $[F(2,5)=128.4$, $p<.05]$. A Newman-Keuls analysis revealed further that performance was significantly higher with line-element samples than with lines $+B L$ and lines $+D L$ compound samples. Also, performance was significantly higher with lines + DL samples than with lines + BL samples. No significant difference in performance was found between $\mathrm{V}$ (56.1\%) and $\mathrm{H}(60.4 \%)$ samples presented in compound with houselight samples $[t(5)=.26, p>.05]$.

The performance of individual subjects is presented in Table 1. The most striking feature of these data is the consistency across subjects. Relative to Figure 1, it can be seen that the group means accurately reflect the performance of each subject under each condition. Also, the deficits for each subject are limited to the stripes component, with performance on the light component remaining at the high levels of accuracy found with element light samples. Thus, all subjects appear to be showing the same asymmetrical deficit.

In order to help interpret the differences in matching accuracy found between trials in which line samples were probed, an analysis was performed on the incidental peck responses to the line samples. More mean pecks were made on element trials, 3.72, than on compound trials, 


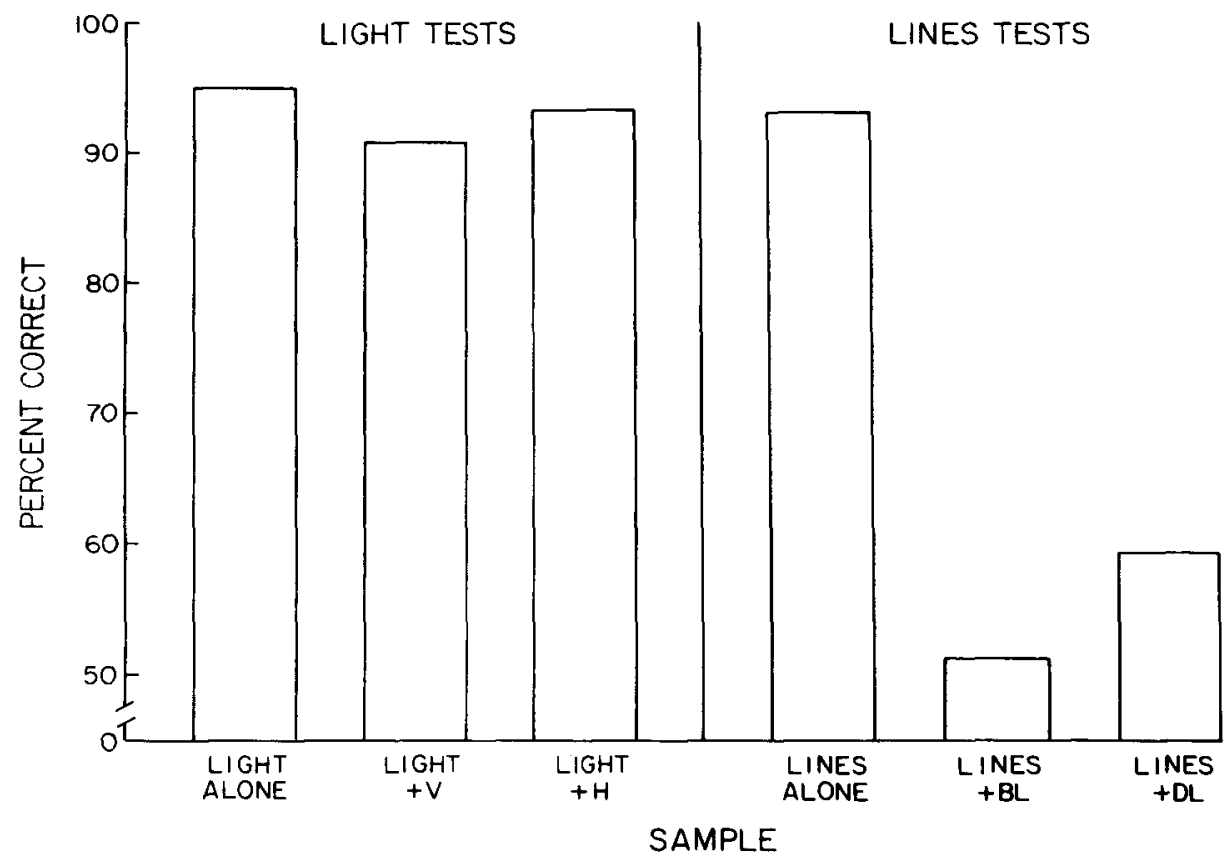

Figure 1. Percentage of correct responses on light tests (left panel) and on lines tests (right panel). On light tests, houselight samples were presented alone or in compound with vertical lines (V) or horizontal lines (H). On lines tests, line samples were presented alone or in compound with a bright houselight (BL) or a dim houselight (DL).

1.15 , and the difference in mean pecks was significant $[t(5)=5.34, p<.05]$.

These results clearly indicate a selective performance deficit. When tested on the line component of a linehouselight compound, pigeons' matching accuracy was significantly inferior to their performance with element line samples. In contrast, there was no difference found in matching accuracy for houselight probes following element and compound samples. This asymmetrical matching deficit is similar to that reported by Kraemer and Roberts (1985), in which auditory signals were matched less well when presented in compound with a visual signal, and visual signals were matched equally well with element and compound samples.

There are several plausible explanations for the present findings. One possibility is that houselight samples were more salient and simply overshadowed the line samples. This account, however, is inconsistent with the fact that both $\mathrm{V}$ and $\mathrm{H}$ samples were higher in luminance than the DL sample $\left(33,35\right.$, and $4 \mathrm{~cd} / \mathrm{m}^{2}$, respectively). Another possibility is that the deficit found with line samples was a generalization decrement associated with the change in stimulus context between element and compound samples (Grant \& MacDonald, 1986). For example, the presence of the bright houselight on $\mathrm{BL}+\mathrm{V}$ and $\mathrm{BL}+\mathrm{H}$ trials may have provided a substantial change in illumination between element line samples and BL + lines samples, which could have deleteriously affected matching accuracy of the line component. Consistent with this explanation would be the finding that matching of the BL sample was unaffected by the presence of a line sample. In this case, the added
Table 1

Percentages of Correct Matching Responses for Individual Subjects in Experiments 1, 2, 3A, and 3B

\begin{tabular}{|c|c|c|c|c|c|c|}
\hline \multirow[b]{2}{*}{ Subject } & \multicolumn{3}{|c|}{ Lines Probed } & \multicolumn{3}{|c|}{ Light Probed } \\
\hline & $\begin{array}{l}\text { Lines } \\
\text { Alone }\end{array}$ & $\begin{array}{l}\text { Lines } \\
+\mathrm{BL} \\
\end{array}$ & $\begin{array}{l}\text { Lines } \\
+\mathrm{DL} \\
\end{array}$ & $\begin{array}{l}\text { Light } \\
\text { Alone }\end{array}$ & $\begin{array}{l}\text { Light } \\
+\mathrm{HS}\end{array}$ & $\begin{array}{l}\text { Light } \\
+ \text { VS }\end{array}$ \\
\hline \multicolumn{7}{|c|}{ Experiment 1} \\
\hline 1 & 93.8 & 54.2 & 57.3 & 93.8 & 97.9 & 96.9 \\
\hline 2 & 85.4 & 52.4 & 56.3 & 96.9 & 93.8 & 92.8 \\
\hline 3 & 98.9 & 53.2 & 70.9 & 95.6 & 94.8 & 93.8 \\
\hline 4 & 87.6 & 53.5 & 68.9 & 96.9 & 91.7 & 87.5 \\
\hline 5 & 94.8 & 54.2 & 56.3 & 89.6 & 84.4 & 78.2 \\
\hline 6 & 93.8 & 51.1 & 61.5 & 95.9 & 95.8 & 96.9 \\
\hline \multicolumn{7}{|c|}{ Experiment 2} \\
\hline 7 & 82.3 & 56.3 & 62.3 & & & \\
\hline 8 & 86.5 & 62.5 & 80.0 & & & \\
\hline 9 & 79.2 & 60.4 & 66.5 & & & \\
\hline 10 & 92.7 & 43.8 & 87.5 & & & \\
\hline 11 & 94.3 & 53.7 & 89.5 & & & \\
\hline 12 & 87.0 & 53.7 & 79.2 & & & \\
\hline \multicolumn{7}{|c|}{ Experiment 3A } \\
\hline 1 & 78.1 & 48.5 & 62.5 & 92.2 & 90.6 & 86.0 \\
\hline 2 & 73.5 & 56.3 & 59.4 & 93.8 & 90.7 & 92.2 \\
\hline 3 & 90.7 & 48.5 & 87.5 & 98.5 & 86.0 & 95.4 \\
\hline 4 & 75.0 & 54.7 & 64.1 & 93.8 & 89.1 & 89.1 \\
\hline 5 & 95.4 & 46.9 & 67.2 & 79.7 & 89.1 & 92.2 \\
\hline 6 & 67.2 & 56.3 & 59.4 & 98.5 & 98.5 & 98.5 \\
\hline \multicolumn{7}{|c|}{ Experiment $3 B$} \\
\hline 7 & 87.5 & 47.7 & 86.8 & & & \\
\hline 8 & 92.2 & 55.5 & 82.0 & & & \\
\hline 9 & 82.8 & 57.8 & 81.3 & & & \\
\hline 10 & 91.7 & 52.1 & 56.3 & & & \\
\hline 11 & 56.5 & 64.6 & 67.8 & & & \\
\hline 12 & 92.5 & 47.5 & 82.5 & & & \\
\hline
\end{tabular}


illumination from the line sample would represent only a minimal change in illumination context from that associated with element BL samples. There are, however, significant problems with this analysis. First, there was a significant deficit found with line samples presented in compound with either a BL or DL sample. Given that the DL sample provided only a small change in illumination between element and compound trials in which line samples were probed, such a change might not be expected to disrupt performance, if the contextual change is responsible for the deficit. An even more compelling case against the contextual change interpretation comes from the failure to find any difference in the matching accuracy with $\mathrm{BL}$ and DL samples presented in compound with lines. If illumination context is the important factor, then a deficit might be expected for the houselight component of DL $+V$ and $\mathrm{DL}+\mathrm{H}$ samples, given that the line component provided a substantial change in illumination relative to DL element samples. Yet DL samples were no more disrupted when compounded with line samples than were BL samples.

A final possibility to be considered is a restricted processing hypothesis. According to this alternative, the asymmetrical deficit resulted from a selective processing of houselights over lines. When presented with compound samples, the pigeons may have restricted processing, on most trials, so that houselight samples were processed to the exclusion of the line samples. Although by itself inconclusive, the finding that fewer pecks occurred to the line samples on compound trials than on element trials is consistent with a restricted processing analysis. Such an interpretation could allow for the deficits to be greater on compound trials with the BL sample than with the DL sample, due perhaps to restricted process being a function of signal intensity, and could also explain why the deficits with the line components were less than complete; accuracy with the line component was above chance performance on $\mathrm{DL}+\mathrm{V}$ and $\mathrm{DL}+\mathrm{H}$ trials. This could be accounted for by assuming that restricted processing did not occur on every trial and was less likely with the DL than with the BL.

\section{EXPERIMENT 2}

An important question for a restricted processing analysis of the effects found in Experiment 1 is why processing would be restricted to houselight samples instead of line samples. One possibility is that houselight illumination dominated processing in part as a result of the signaling function served by the BL and DL samples. Conversely, restricted processing may be independent of the information value provided by a stimulus; it may instead represent an inherent priority for processing houselight signals over pattern stimuli presented on a pecking key. Experiment 2 was designed to answer this question. A separate group of pigeons was trained on a symbolic simultaneous matching-to-sample problem. They were trained to peck appropriate color-comparison keys follow- ing line samples and then were tested with element and compound stimulus presentations. The compound stimuli consisted of either $\mathrm{V}$ or $\mathrm{H}$ samples together with either bright or dim houselight illumination. If the restricted processing effect obtained in Experiment 1 was caused by the signaling function of the houselight samples, then the effect would not be expected to appear in the present situation.

\section{Method}

Six experimentally naive adult Silver King pigeons served as subjects. All birds were housed and maintained in the same manner as the subjects in Experiment 1. The apparatus used in the previous experiment was employed. After being hand-shaped to keypeck, 3 of the pigeons were trained to peck a red side key following a $\mathrm{V}$ sample and a green side key following a $\mathrm{H}$ sample. The other 3 birds were trained to peck a blue side key following a $\mathrm{V}$ sample and a yellow side key following a $\mathrm{H}$ sample. The acquisition criterion was set at three consecutive sessions in which matching was at or above $85 \%$ correct choices.

Experimental testing involved 32 sessions, in which both element and compound stimulus displays were presented. Of the 48 trials presented in each session, 16 were element trials, with $\mathrm{V}$ and $\mathrm{H}$ samples each presented for eight trials. The remaining 32 trials involved compound stimuli, with eight presentations of each compound $(V+B L, V+D L, H+B L$, and $H+D L)$. The left/right spatial position of the correct side key was balanced across trial types. Two different randomly arranged trial orders alternated regularly over the test sessions. All intra- and intertrial events were programmed as in Experiment 1.

\section{Results and Discussion}

The mean sessions to criterion on the matching-tosample problem was 34.2 . The mean percentages of correct choices for the various experimental trials are presented in Figure 2. The differences between the three types of test trials were found to be significant $[F(2,5)$ $=24.08, p<.01]$. A Newman-Keuls analysis indicated that matching accuracy was significantly lower with lines +BL samples than with lines $+D L$ or lines-alone samples. Performance on the latter two conditions did not differ significantly. It was found also that the number of mean pecks to the line samples was greater on element trials, 5.32, than on compound trials, 1.74 , and that the difference between means was significant $[t(5)=3.79$, $p<.01]$.

Accuracy data for individual subjects are shown in Table 1 . It is interesting to note that every subject performed best in the lines-alone condition and worst in the lines +BL condition. Although the Newman-Keuls test showed no difference between the means of lines $+D L$ and lines-alone conditions, all 6 birds scored lower in the lines + DL condition than in the lines-alone condition.

The results of this experiment reveal that houselight illumination during presentation of a line sample disrupted matching accuracy, but only with a bright houselight; the presence of a dim houselight did not have a statistically significant effect, although some loss of accuracy was noted. As in Experiment 1, fewer peck responses to a line sample occurred when a houselight was concurrently available. Thus, despite the absence of any signal value, 


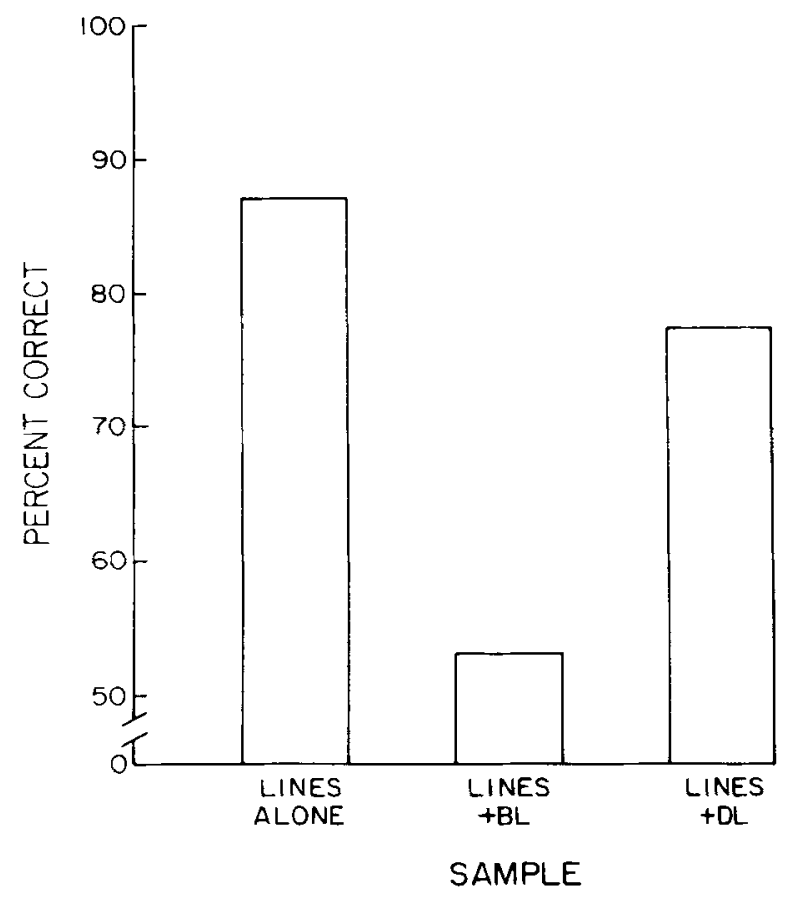

Figure 2. Percentage of correct responses on lines tests when line samples were presented alone or in compound with a bright houselight (BL) or a dim houselight (DL).

houselight illumination was again found to disrupt matching accuracy when lines were presented as samples. This observation suggests that there may be something about houselight ilumination that inherently directs pigeons' attention away from line samples presented on a pecking key. A similar effect was found for houselight illumination presented during visual and auditory samples (Kraemer \& Roberts, 1985). The only difference between the present findings and those of Experiment 1 is that the dim houselight did not disrupt matching accuracy significantly in this experiment.

\section{EXPERIMENTS 3A AND 3B}

We have chosen to emphasize a distinction between restricted processing and shared attention, which will be further explicated in the General Discussion. It is possible that a shared-attention interpretation may still be viable. If it is assumed that pigeons attend sequentially to components of a compound sample, because they cannot attend to the components simultaneously, then perhaps with relatively short sample durations there is insufficient time to distribute attention to all components; it may be that only the component attended to first is processed effectively. For example, perhaps pigeons in Experiments 1 and 2 attended to houselight first and did not have sufficient time to attend to the lines in a houselight-lines compound. Such an interpretation remains plausible despite the fact that a simultaneous matching procedure was used. It has been argued that simultaneous matching-to-sample should obviate any processing-time limitations, because the subject has an unrestricted duration during which to process the sample (Cox \& D'Amato, 1982). However, this argument assumes that sample processing is not controlled by event characteristics other than sample duration. It may be that pigeons automatically terminate sample processing upon the onset of comparison stimuli. Regardless of the absence of any explicit limitations on sample duration during simultaneous matching, there may be de facto limitations.

A stronger test of the shared-attention analysis would be to examine directiy the effect of sample duration on compound matching. A shared-attention analysis would predict that longer sample durations would allow the subject more time to distribute attention to all components of a compound (Lamb \& Riley, 1981). It would therefore be expected that the matching deficit found with lines in Experiment 1 would be reduced or eliminated by extending sample durations. In contrast, a restricted processing interpretation would predict little or no influence of sample duration. This position holds that animals select certain information for processing to the exclusion of other information and that this selection process cannot be overcome by additional processing time. We tested these two competing hypotheses by comparing matching accuracy for compound and element samples presented for either short (4-sec) or long (12-sec) durations.

\section{Method}

All birds used in Experiment 1 were the subjects in Experiment $3 \mathrm{~A}$, and all birds used in Experiment 2 were the subjects in Experiment 3B. The only difference between the two experiments was that the subjects in Experiment $3 \mathrm{~A}$ were tested on matching both houselight and line samples, whereas the subjects in Experiment 3B were tested only for matching of line samples. The pigeons in both experiments were given 32 sessions with 48 trials/session. In Experiment $3 \mathrm{~A}$, each of the $\mathrm{BL}, \mathrm{DL}, \mathrm{V}$, and $\mathrm{H}$ element samples was tested on four trials, and each of the $B L+V, B L+H, D L+V$, and $\mathrm{DL}+\mathrm{H}$ compound samples was tested on eight trials; on half of the compound trials, the houselight component was probed; on the other half, the line component was probed. The pigeons in Experiment 3B were tested on 16 element stimulus trials, half of which involved $V$ samples and the other half, $H$ samples. Each of the $\mathrm{BL}+\mathrm{V}, \mathrm{BL}+\mathrm{H}, \mathrm{DL}+\mathrm{V}$, and $\mathrm{DL}+\mathrm{H}$ compound stimuli was tested on eight trials. On half of all the trial types tested in both of the experiments, samples were presented for $4 \mathrm{sec}$ before the onset of the comparison keys; on the remaining trials, samples were presented for $12 \mathrm{sec}$ prior to onset of the comparison keys. The left/right location of the correct comparison was balanced across trial types. The same general procedure that had been used in the previous two experiments again was followed. Two different randomly arranged trial orders alternated regularly across sessions.

\section{Results}

Experiment 3A. The mean percentage of correct choices for each of the trial types tested is displayed in Figure 3. It can be seen that line samples were matched less accurately when presented in compound with a houselight sample, whereas houselights were matched equally well on element and compound trials. Also, there appears to be no noticeable difference between trials tested after 


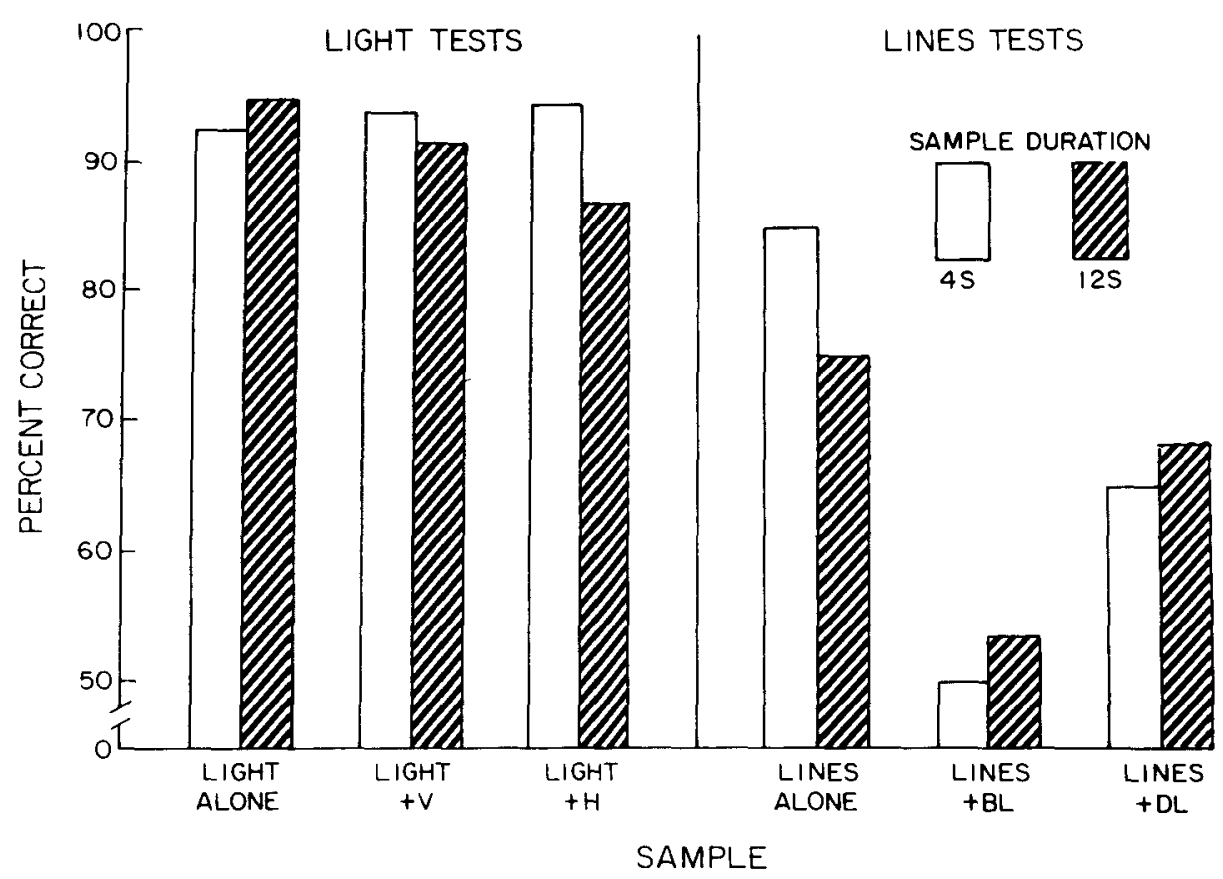

Figure 3. Percentage of correct responses in Experiment 3A, with light tests presented in the left panel and lines tests presented in the right panel. On light tests, houselight samples were presented alone or in compound with vertical lines (V) or horizontal lines (H). On lines tests, line samples were presented alone or in compound with a bright houselight (BL) or a dim houselight (DL).

short and long sample durations. A repeated measures analysis of variance performed on these data included as factors sample probed (houselight and lines), sample display (element, Compound 1, and Compound 2), and sample duration ( 4 and $12 \mathrm{sec})$. Significant main effects were obtained for sample probed $[F(1,5)=147.4, p<.01]$ and sample display $[F(2,10)=22.6, p<.01]$. The sample probed $\times$ sample display interaction also was significant $[F(2,10)=15.8, p<.01]$. The main effect of sample duration and the remaining interactions were not significant. Simple main effects analyses revealed that the sample probed $X$ sample display interaction was due to significant differences among the three types of line samples $[F(2,5)=61.5, p<.01]$ and no significant differences in performance among the three types of houselight samples $(F<1.0)$. A Newman-Keuls analysis revealed further that performance was significantly higher on linesalone trials than on either lines +BL or lines $+D L$ trials. Also, accuracy was significantly higher on lines $+D L$ trials than on lines $+B L$ trials. Percentages of correct responses are shown for individual subjects in Table 1, with performance averaged over the 4- and 12-sec sampleexposure durations. The pattern of differences found in the mean scores is reflected in the performance of each subject.

Experiment 3B. The mean percentage of correct choices for each trial type tested is displayed in Figure 4. It can be seen that matching was affected by the presence of houselight illumination but appears to have been uninfluenced by sample duration. A repeated measures analysis of variance confirmed these observations. Significant differences among the three trial types tested were found $[F(2,10)=81.1, p<.01]$. The effect of sample duration and the interaction between sample duration and sample probed were not significant. A Newman-Keuls analysis indicated that performance with lines-alone samples was significantly higher than with lines $+B L$ and lines + DL samples. It can be seen in Table 1 that the mean differences were found also in the scores of individual subjects, with the exception of the low score in the linesalone condition shown by Subject 11 .

\section{Discussion}

These results show clearly that sample duration had no significant influence on matching performance. Once again, it was found that houselight illumination disrupted matching accuracy for line samples. The interfering effect of a houselight was found both in groups trained and in groups not trained to match houselight samples. Also, for both groups, a bright houselight was more disruptive than a dim houselight, but both groups showed significant interference with the dim houselight, which contrasts with the findings of Experiment 2. Thus, it appears that pigeons selectively process a houselight over a visual pattern presented on a pecking key, even with long exposure to the sample prior to testing. 


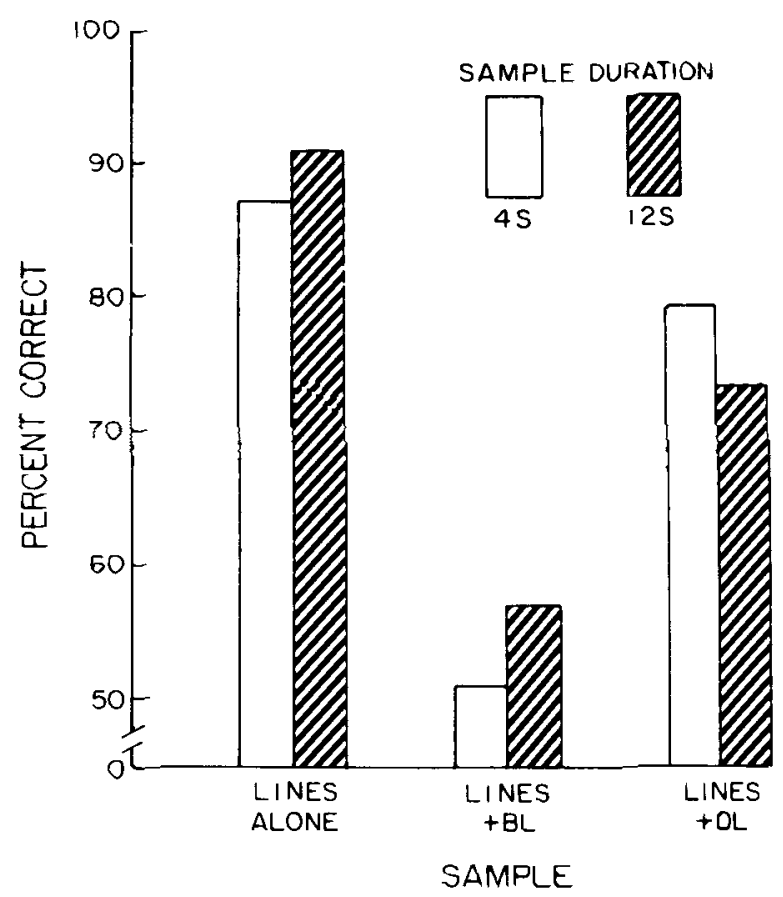

Figure 4. Percentage of correct responses on lines tests in Experiment 3B. Line sample stimuli were presented alone or in compound with a bright houselight (BL) or a dim houselight (DL).

\section{GENERAL DISCUSSION}

A number of studies have reported a matching deficit with compound stimuli in matching-to-sample (Maki \& Leith, 1973; Maki et al., 1976; Roberts \& Grant, 1978). Most of these studies have used an identity matching procedure and have presented samples on pecking keys. Under these conditions, a symmetrical deficit usually has been found, in which matching accuracy was reduced for each component of the compound relative to trials in which these components were presented as element samples. The typical shared-attention account of this effect proposes that organisms have a limited attentional capacity and that this capacity is exceeded by information in a compound sample. Attention must be shared across components, and, consequently, each component does not receive the degree of information uptake it would otherwise receive if presented as an element. It is this diminished attention that is held to be responsible for the compound deficit (Riley, 1984; Riley \& Leith, 1976; Riley \& Roitblat, 1978). The problem has been that, due to the nature of the identity matching-to-sample task, a generalization decrement interpretation usually has been equally tenable (Cox \& D'Amato, 1982; Roberts \& Grant, 1978; Santi et al., 1982). The physical dissimilarity of the compound samples and comparisons may adversely affect performance.

By using a symbolic matching procedure in the present experiments, similarity between sample and comparison stimuli was avoided. It was found that even with the problem of generalization decrement seemingly obviated, a deficit on compound trials relative to element trials was found. In all three experiments, it was found that line samples presented on a key were matched less well when presented in compound with a houselight than when presented alone.

Although generalization decrement cannot easily account for these results, it is also apparent that a sharedattention analysis is equally unsatisfactory. If compound samples force animals to share attention across components, and if this is what is responsible for the obtained deficit, then a deficit would be expected with both components of a compound. Furthermore, it would be expected that increased sample processing time should diminish or eliminate the deficit. Finally, if subjects were not trained to match one component of a compound, that component should not compete for processing time, and little deficit in matching the other member of the compound should be found. Contrary to these predictions, an asymmetrical deficit was found that involved lines only, and the extent of the deficit was equivalent with long and short sample durations and under conditions in which the houselight was a sample stimulus and under conditions in which it was not.

As an alternative to shared-attention and generalizationdecrement analyses, an account may be offered in terms of restricted processing. We have chosen to avoid the term "selective attention" because of its theoretical counotations, which imply something different from our intentions. The term "selective attention" generally has been used to suggest a special case of shared attention. It assumes that limited attentional capacity forces animals to distribute their attention across components of a compound stimulus. For some compounds, this distribution is such that attention is restricted exclusively to one of the components. This view regards selective attention as a special case of attentional allocation and is assumed to be a result of a processing limitation. As an example of data offered in support of this model of selective attention, training with one set of sample stimuli may strengthen control by those stimuli in a compound and weaken control by other stimuli in the compound (Leith \& Maki, 1975; Riley \& Roitblat, 1978). It is still difficult for such a model to account for the findings reported here, particularly the observation that deficits were found both with and without previous training to match the houselight as a sample stimulus.

We prefer to conceptualize restricted processing as a processing strategy rather than as a processing limitation. This approach assumes that animals may select signals for processing for reasons other than just information overload. For example, signals may be selected for input on the basis of the design characteristics of the organism's information processing system, the nature of the signals themselves, or the organism's previous experience with the signals. Thus, although both shared-attention and restricted processing imply a selective-processing mecha- 
nism, the latter approach characterizes this selection as an information priority control rather than as an information filter.

It appears that restricted processing offers the most effective account of the current findings. Such an interpretation suggests that, on most trials, pigeons confronted with a houselight-line compound selected the houselight component for processing while ignoring the line component. The observation that a dim houselight did not interfere with line matching as much as a bright houselight did suggests that not all houselight intensities produced restricted processing on all trials. Although the bright houselight may have commanded virtually total attention, the dim houselight may have allowed processing of the line component on some trials. It is interesting that dim houselight in compound with lines generally interfered with line processing but that the presence of lines never interfered with dim houselight processing, even though both stimuli were of approximately equal brightness. An unpatterned light source, then, may command greater processing priority than a patterned light source.

It is interesting that input selection is clearly an inefficient strategy; with the simultaneous matching procedure or with a long sample duration, pigeons had ample time to process both sample components before responding. Even when subjects had not been trained to match houselight samples, interference appeared. Such observations suggest strongly that pigeons selectively processed the houselight, and that such restricted processing was little modified by the training and testing variables manipulated in these experiments. Very similar interference effects of visual signals on the processing of auditory sample stimuli in visual-auditory compounds were found in the Kraemer and Roberts (1985) studies.

The effects reported here and by Kraemer and Roberts (1985) both suggest rigid or hard-wired preferences for processing certain kinds of information over others. We may inquire as to why shared-attention effects have been found in experiments involving visual compounds on a single key but were not found in our experiments. Distinctions between unified and separable compounds (Garner, 1970) or between input selection and analyzer selection (Treisman, 1969) may be important here. Riley and Leith (1976) have discussed these distinctions in detail, and Lamb and Riley (1981) have shown that increasingly separating line and color components on a key increases the magnitude of shared-attention effects. The dramatic restricted processing effects found here and by Kraemer and Roberts (1985) arise only when the components of a compound are presented at different points in space. Strong innate preferences for attending to one form of stimulation over another may be revealed only when sources of stimulation are clearly separated in these ways.

Grant and MacDonald (1986) recently have offered evidence to suggest that the compound element difference found with lines superimposed on a colored key arises from configurational perception and generalization decre- ment. Specifically, Grant and MacDonald found that pigeons trained to match compound sample stimuli and then tested with compounds and elements showed better matching with compounds than with elements. They suggested that pigeons do not decompose line-color compounds into components and that the element-compound difference arises from generalization decrement between the element sample stimuli used in training and the compound sample stimuli used in testing.

If Grant and MacDonald's analysis is accurate, the symmetrical losses seen with line-color compounds may not represent shared attention but only equivalent degrees of generalization decrement. An application of the configurational analysis to the lines-houselight or auditory-visual compounds would seem problematic, since asymmetrical deficits were found in these experiments. It may be argued that the separation of elements by modality or point in space at which stimuli appear removes the possibility of configurational perception and exposes more natural attentional processes. If this is the case, our work thus far suggests that restricted processing or dominance by one source of stimulation is the rule and that shared attention is uncommon.

Although a complete explanation of the attentional phenomena discussed here is not at hand, it seems clear that the limited-channel capacity or bottleneck model of attention (Riley \& Leith, 1976) has been brought into serious question as a general account of compound element differences in pigeon matching experiments. It appears that additional concepts, such as restricted processing and configuration, will have to be invoked to deal with recent findings.

\section{REFERENCES}

Cox, J. K., \& D'Amato, M. R. (1982). Matching to compound samples by monkeys (Cebus apella); Shared attention or generalization decrement. Joumal of Experimental Psychology: Animal Behavior Processes, 8, 209-225.

GARNER, W. R. (1970). The stimulus in information processing. American Psychologist, 25, 350-358.

Grant, D. S., \& MacDonald, S. E. (1986). Matching to element and compound samples in pigeons: The role of sample coding. Journal of Experimental Psychology: Animal Behavior Processes, 12, 160-171.

Kraemer, P. J., \& RoberTs, W. A. (1985). Short-term memory for simultaneously presented visual and auditory signals in the pigeon. Journal of Experimental Psychology: Animal Behavior Processes, 11, 137-151.

LAMB, M. R., \& Riley, D. A. (1981). Effects of element arrangement on the processing of compound stimuli in pigeons (Columba livia). Journal of Experimental Psychology: Animal Behavior Processes, 7, 45-58.

LEITH, C. R., \& MAKI, W. S. (1975), Attention shifts during matchingto-sample performance in pigeons. Animal Leaming \& Behavior, 3, 85-89.

MAKI, W. S., \& LEITH, C. R. (1973). Shared attention in pigeons. Journal of the Experimental Analysis of Behavior, 19, 345-349.

MAKI, W. S., \& LEUIN, T. C. (1972). Information processing by pigeons. Science, 176, 535-536.

MAKI, W. S., Riley, D. A., \& Leith, C. R. (1976). The role of test stimuli in matching-to-compound samples. Animal Learning \& Behavior, 4, 13-21 
Ruley, D. A. (1984). Do pigeons decompose stimulus compounds? In H. L. Roitblat, T. G. Bever, \& H. S. Terrace (Eds.) Animal cognition (pp. 333-348). Hillsdale, NJ: Erlbaum.

Riley, D. A., \& Leith, C. R. (1976). Multidimensional psychophysics and selective attention in animals. Psychological Bulletin, 83, 138-160.

Riley, D. A., \& Roitblat, H. L. (1978). Selective attention and related cognitive processes in pigeons. In S. H. Hulse, H. Fowler, \& W. K. Honig (Eds.), Cognitive processes in animal behavior (pp. 249-276). Hillsdale, NJ: Erlbaum.

Roberts, W. A., \& GraNt, D. S. (1978). Interaction of sample and comparison stimuli in delayed matching to sample with pigeons. Journal of Experimental Psychology: Animal Behavior Processes, 4, 68-82.
Roberts, W. A., \& Kraemer, P. J. (1982). Some observations of the effects of intertrial interval and delay on delayed matching-to-sample with the pigeon. Journal of Experimental Psychology: Animal Behavior Processes, 8, 342-352.

Santi, A., Grossi, V., \& Gibson, M. (1982). Differences in matching to-sample performance with element and compound sample stimuli in pigeons. Learning \& Motivation, 13, 240-256.

Treisman, A. (1969). Strategies and models of selective attention. Psychological Review, 76, 282-299.

(Manuscript received February 10, 1986; revision accepted for publication September 3, 1986.) 